\title{
Newborn low birth weight: do socio- economic inequality still persist in India?
}

\author{
Prem Shankar Mishra ${ }^{1} \mathbb{D}$, Debashree Sinha², ${\text { Pradeep } \text { Kumar }^{3} \mathbb{B} \text {, Shobhit Srivastava }}^{3^{*} \mathbb{D} \text { and Rahul Bawankule }}{ }^{4}$
}

\begin{abstract}
Background: The incidence of preterm birth and subsequent low birth weight (LBW) are vital global public health issues. It contributes to high infant and child mortality in the early stages of life and later on in adult life; it increases the risk for non-communicable diseases. The study aims to understand the socio-economic status-related inequality for LBW among children in India. It hypothesises that there is no association between the socio-economic status of the household and the newborn's LBW in India.

Methods: The study utilised data from the fourth round of the National Family Health Survey, a national representative cross-sectional survey conducted in 2015-16 ( $N=127,141)$. The concentration index (CCI) and the concentration curve (CC) measured socio-economic inequality in low birth status among newborns. Wagstaff decomposition further analysed key contributors in CCl by segregating significant covariates.

Results: About $18.2 \%$ of children had low birth weight status. The value of concentration was -0.05 representing that low birth weight status is concentrated among children from lower socio-economic status. Further, the wealth quintile explained $76.6 \%$ of the SES related inequality followed by regions of India ( $-44 \%)$ and the educational status of mothers (43.4\%) for LBW among children in India. Additionally, the body mass index of the women (28.4\%), antenatal care (20.8\%) and residential status (-15.7\%) explained SES related inequality for LBW among children in India.

Conclusion: Adequate attention should be given to the mother's nutritional status. Awareness of education and usage of health services during pregnancy should be promoted. Further, there is a need to improve the coverage and awareness of the ante-natal care (ANC) program. In such cases, the role of the health workers is of utmost importance. Programs on maternal health services can be merged with maternal nutrition to bring about an overall decline in the LBW of children in India.
\end{abstract}

Keywords: Low birth weight, Socio-economic inequality, Concentration index, Decomposition, India

\section{Background}

The incidence of preterm birth and subsequent low birth weight (LBW) are vital global public health issues [1]. It contributes to a high infant and child mortality in the early stages of life and later on in adult life; it increases the risk for non-communicable diseases [1-3]. The incidence of LBW is defined as the proportion of newborns

*Correspondence: shobhitsrivastava889@gmail.com

${ }^{3}$ Department of Mathematical Demography \& Statistics, International Institute for Population Sciences, Mumbai, Maharashtra 400088, India Full list of author information is available at the end of the article weighing less than $2500 \mathrm{~g}(<5.5 \mathrm{lbs})$, regardless of gestational age [2]. Worldwide, in 2013, an estimation showed that nearly 22 million newborns (nearly $16 \%$ of all babies born globally) were LBW [2]. The majority of LBW occurs in low and middle-income countries, and it occurs to the marginalized and vulnerable sub-population groups [1, $4]$. The goal is to achieve a $30 \%$ reduction in the number of infants born with a weight less than $2500 \mathrm{~g}$ by 2025 [2], however, a lack of policy consistency and implementation strategy across low and middle-income countries are unable to achieve it. Moreover, regional variations in LBW are found uneven, and some of the regions like 
South Asia, Sub-Saharan Africa are facing higher severity in newborn LBW $[1,4]$. Further, regional level estimates show that the occurrence of LBW in South Asia is 28 and $13 \%$ in Sub-Saharan Africa, respectively [2]. Within the southern region, India contributes the highest infant LBW $[1,5,6]$; therefore, it becomes important to understand the co-existing determinants that affect LBW in India and across regions.

LBW is one of the most important indicators to measure the socio-economic development of the community. The mother's socio-economic characteristics are directly linked to the child's health and well-being. Studies have shown that mother's education, knowledge and media exposure are significantly linked to reducing LBW in low and middle-income countries, including India $[4,5,7]$. In India, women have been historically deprived on multiple socio-political and economic grounds that have further put their children at high risk, such as preterm birth and LBW [5, 8-10]. Furthermore, there is a substantial variation in the prevalence of LBW across different socio-economic groups and regions in India $[5,11]$. However, the majority of LBW is found among the most deprived communities [9, 12-14]. Although LBW is the outcome of multi-faceted risk factors yet very few studies have tried to understand it. Further, low resource setting areas are also vulnerable to the high occurrence of LBW [15].

Since the mother's health and nutritious characteristics play a significant role in the outcomes of preterm birth and LBW among their children, it is, therefore, essential to provide proper health, diet, and nutritional care to mothers during pregnancy $[1,2,7,16]$. The mother's nutritional deficiency and poor healthcare services put the baby at risk, such as preterm birth or LBW. Further, providing reproductive health services such as contraception to delay age at first pregnancy and to increase intervals between births can reduce the chance of delivering an LBW newborn $[8,17,18]$. Moreover, for a healthy baby, mothers need better health care services (full antenatal care), proper nutrition, and a clean environment $[1$, 6 , 7]. Smoking and drinking alcohol among women can further create a risk for LBW [19].

The incidence of newborn LBW is an important predictor of newborn health, growth, cognitive development, and survival [2]. The mother's continuity of care may reduce newborn LBW. Although there are several consecutive interventions to mother and child to enhance child health and survivorship, however, in India, lack in pre-pregnancy interventions, full antenatal care interventions, and interventions at the community level contribute to adverse outcomes of a newborn $[5,7,15]$. Nevertheless, occurring LBW among newborn babies constitutes several other problems that have been recognised as poor maternal and child care in the community, poor referral system, poor health infrastructure, homebased care, and lack of surveillance and data management regarding it [1, 20-22].

In this way, there are many predisposing risk factors that influence LBW in India. Very few studies have compared the prevalence of LBW across different gradients of women and children, such as socio-economically, demographically, and environmentally in India and across regions. A dearth of literature is found to understand the multiple determinants that are pervasive to LBW in India and across regions. Therefore, the study aims to understand the socio-economic status-related inequality for LBW among children in India. The study further hypothesises that there is no association between the socio-economic status of the household and the newborn's LBW in India.

\section{Methods}

We used data from the fourth round of the National Family Health Survey (NFHS), a nationally representative cross-sectional survey conducted in 2015-16. The International Institute for Population Sciences (IIPS) in Mumbai has conducted four rounds of NFHS surveys under the aegis of the Indian Ministry of Health and Family Welfare (MoHFW). The NFHS-4's main goal was to offer vital statistics on health and family welfare, as well as data on emerging difficulties in these areas. As a result, the survey collects data on population health and nutrition for men, women, and children in all 36 states and union territories of India. To obtain estimates for India as a whole and its states, the NFHS-4 used a two-stage stratified sampling approach. The details can be obtained from elsewhere [23]. With a response rate of $98 \%, 97 \%$, and $92 \%$, the survey collected data from 601,509 households, 699,686 women, and 112,122 men.

For the newborn's birth weight, a question was asked to the mothers 'Was (NAME) weighed at birth? If the response was yes, further, 'How much did (NAME) weigh? The responses were recorded as weight in kilograms from card and kilograms from recall. Among 259,627 sampled children, 57,451 children were not weighed at birth, and 8818 were "don't know" cases. After excluding children whose birth weight data were not available, finally, we had 193,358 children with LBW data. In order to obtain better estimates for the body mass index (BMI), the study excluded women who were presently pregnant and women who had given birth in the previous 2 months. The NFHS- 4 gathered data on the three youngest children from the birth history who were born within the survey's reference period. To eliminate recall bias, we only included the most recent birth in the 5 years before to the survey. Also, for the second and third most recent births in history, information on 
Antenatal Care (ANC) associated characteristics was not accessible. As a result, we had a total of 127,141 index children in our analytical sample. Table S1 contains the strobe guidelines (supplementary file).

\section{Outcome variable}

All newborns weighing less than $2.5 \mathrm{~kg}(<2500 \mathrm{~g})$ at the time of birth was considered low birth weight (LBW) children. The outcome variable was dichotomous: 1 'yes' if newborns weighing less than $2.5 \mathrm{~kg}$ at the time of birth and 0 'no', otherwise [12, 24-26].

\section{Exposure variables}

Based on the literature, we identified potential risk factors of LBW and included them as exposure variables in the analysis $[1,2,5,9,16,22-24]$. The exposure variables included age of women at index birth $(\leq 19,20-24,25-29$, $30-35$ and $35+$ years), body mass index (underweight: $\leq 18.5 \mathrm{~kg} / \mathrm{m}^{2}$, normal: 18.5 to $<24.99 \mathrm{~kg} / \mathrm{m}^{2}$ and overweight/obesity: $\geq 25.0 \mathrm{~kg} / \mathrm{m}^{2}$ ) [27], and antenatal care (no, partial, and full). The study created a composite variable 'birth order and interval' using the information on the birth order number and preceding birth interval from the index child. Further, we categorised it as 'first birth order', 'second and third birth order and birth interval lesser than 24 months $(2-3 \&<24)$,' 'second and third birth order and birth interval greater than 23 months (2-3 $\&>23$ )' 'four and above birth order and birth interval lesser than 24 months $(\geq 4 \&<24)$,' 'four and above birth order and birth interval greater than 23 months $(\geq 4$ \& $>23$ )'. Other predictors were education (no education, primary, secondary, and higher), caste (scheduled caste (SC), scheduled tribe (ST), other backward class (OBC), and others) [28], and religion (Hindu, Muslim, and others (including Christian, Sikh, Buddhist/Neo-Buddhist, Jain, Jewish, Parsi/Zoroastrian, no religion, and others). A household's wealth index was calculated in the survey by combining household amenities, assets, and durables and characterising households in a range varying from the poorest to the richest, corresponding to wealth quintiles ranging from the lowest to the highest [29]. Further, the place of residence (urban and rural), and sex of the child (male and female) were included. Geographical regions were coded as North, Central, East, Northeast, West, and South. The source of drinking water was coded into two categories: unimproved and improved [30]. We included public taps, piped water, tube wells, boreholes, standpipes, protected dug wells and springs, rainwater, and community reverse osmosis (RO) plants as an improved source of drinking water. Similarly, the type of toilet facility was coded as unimproved and improved [30]. The flush/pour flush toilets to piped sewer systems, septic tanks, and pit latrines; ventilated improved pit
(VIP)/biogas latrines; pit latrines with slabs; and twin pit/ composting toilets were included as an improved type of toilet facility. The type of cooking fuel was grouped as unclean and clean [30]. We termed cooking fuel as clean if households used electricity, LPG/natural gas, biogas for cooking purposes. Finally,a complete ANC was defined as a mother who had four or more antenatal visits, at least two tetanus toxoid shots, and took iron and folic acid pills or syrup for 100 days or more during their most recent live birth in the 5 years before to the survey.

\section{Statistical analysis}

The distribution of the study population was depicted using descriptive statistics. The factors linked with the outcome variable were also identified using bivariate and multivariate logistic regression analysis. To further understand the relationship (significant or not significant) between outcome variables and predictors, a Chisquare test was used.

\section{Concentration index}

The wealth quintile was the most important factor in determining a family's economic state. To undertake decomposition analysis and produce the concentration index, we first calculated the wealth score (CCI). The children were then graded and divided into five equal categories, each having $20 \%$ of the children, based on their wealth ratings $[31,32]$. To quantify socio-economic inequality in LBW babies in India, the concentration index and concentration curve (CC) were calculated [28, $33,34]$. The concentration index is calculated by dividing the area between the concentration curve and the line of equality by twice the weighted covariance between the result and fractional rank in the wealth distribution divided by the variable mean $[31,32]$.

The concentration index can be written as follows:

$$
C=\frac{2}{\mu} \operatorname{cov}\left(y_{i}, R_{i}\right)
$$

Where $C$ is the concentration index; $y_{i}$ is the outcome variable index; $\boldsymbol{R}$ is the fractional rank of individual $\boldsymbol{i}$ in the distribution of socio-economic position; $\boldsymbol{\mu}$ is the mean of the outcome variable of the sample, and cov denotes the covariance [35]. The index value lies between -1 to +1 .

The concentration index takes a negative value if the curve is above the line of equality, suggesting a disproportionate concentration of inequality among the poor (pro-rich) [31, 32]. If the curve falls below the line of equality, the concentration index is positive, suggesting that inequality is concentrated disproportionally among the rich (pro-poor) [31,32]. The concentration index is zero when there is no socioeconomic disparity [31,32]. 
The CI value indicates the degree of socioeconomic disparity. The greater the absolute value, the more inequities there are.

\section{Decomposition of the concentration index}

Wagstaff decomposition methodology was used to decompose the concentration index [35]. The concentration index could be broken down into the contributions of each aspect to income disparities, according to Wagstaff's decomposition [36]. Each contribution is determined by the health sensitivity of that socioeconomic component as well as the degree of income disparity in that factor. Based on the linear regression relationship between the outcome variable $y_{i}$, the intercept $\alpha$, the relative contribution of $x_{k i}$ and the residual error $\varepsilon_{i}$

$$
y_{i}=\alpha+\sum \beta_{k} x_{k i}+\varepsilon_{i}
$$

Where $\varepsilon_{i}$ is an error term, given the relationship between $y_{i}$ and $x_{k i}$, the CCI for y (C) can be rewritten as

$$
C=\sum\left(\frac{\beta_{k} \bar{x}_{k}}{\mu}\right) C_{k}+\frac{G C \varepsilon}{\mu} / \mu
$$

Where $\mu$ is the mean of $y_{i}, \bar{x}_{k}$, is the mean of $x_{k}, \beta_{k}$ is the coefficient from a linear regression of outcome variable, $C_{k}$ is the concentration index for $x_{k}$ (defined analogously to $\mathrm{C}$, and $\mathrm{GC} \varepsilon$ is the generalised concentration index for the error term $\left(\varepsilon_{i}\right)$.

Here $C$ is the outcome of two components: First, there are the determinants, or 'explained' factors, which are comparable to the weighted accumulation of the regressor's concentration indices, where one unit change in the outcome variable corresponds to one unit change in the explanatory variable $[31,32]$. The explained factors indicate that the proportion of inequalities in the outcome (LBW) variable is explained by the selected explanatory factors, i.e., $\mathrm{x}_{\mathrm{k}}$. Second, a residual or 'unexplained' factor $\left(\frac{G C \varepsilon}{\mu} / \mu\right)$, indicating the inequality in health variables that cannot be explained by selected explanatory factors across various socio-economic groups [35]. The percentage contribution column should be interpreted as the percentage contribution of factors that explain SESrelated inequality in LBW among Indian children. The overall contribution is calculated using the negative and positive signs, which is dependent on the table's sign elasticity and CCI $[31,32]$. The absolute contribution is the product of elasticity and CCI. Furthermore, dividing the aggregate absolute contribution by the absolute contributions of the various variables yields the individual contribution. As a result, the elasticity and CCI define the size of the percentage contribution [33].

\section{Results}

The percentage distribution of the study population by background characteristics is presented in Table 1. About $2.3 \%$ of women interviewed had their age at index birth of 35 years and above. Nearly $25 \%$ of women were underweight, and $18 \%$ were either overweight or obese. Only $24 \%$ of women received full ANC, whereas $6 \%$ received no ANC. Almost $9 \%$ of women had children with fourth birth order and birth interval of more than 24 months. About $21 \%$ of women had no education in contrast to $15 \%$ who had completed higher education. About 16\%, $45 \%$ and $57 \%$ of households had no improved drinking water, no improved toilet facility and unclean cooking fuel facility, respectively.

The percentage distribution of LBW among children by background characteristics in India is presented in Table 2. The prevalence of LBW was high among children whose mother had an age of index birth below or equaled 19 years (19.9\%). The underweight women had a higher LBW prevalence in their children (21.1\%). Mother's with no ANC reported higher LBW prevalence among their child (22.9\%). The prevalence of LBW was higher among children from fourth birth order and birth interval less than 24 months $(20.3 \%)$. Mother's with no or primary education reported higher LBW prevalence among their child (19.4\% and 19.8\%), respectively. The prevalence of LBW among children was considerably higher in rural areas $(17.8 \%)$ compared to urban areas. Female children had a higher prevalence of LBW (18.9\%) than male children. Women from the northern and eastern regions of India reported a higher prevalence of LBW among their children (19.8\% and 19.3\%), respectively. Children from the household with not improved toilet facility had a higher prevalence of LBW (18.8\%). Households with unclean cooking fuel had a higher prevalence of LBW in children (18.3\%) than children in households with clean cooking fuel.

Table 3 presents the estimates from logistic regression analysis for LBW children by their background characteristics. It was found that women who gave their index birth at the age of 20-24years had an 18\% lower likelihood to have children with LBW status than women who gave birth at age 19years or less [OR:0.82, CI:0.79-0.86]. Women with underweight as BMI status had a higher likelihood to have children with LBW status than women with normal BMI status [OR: 1.27, CI: 1.23-2.32]. Children whose mothers had full ANC had lower odds of LBW compared to those who had no ANC [OR: 0.64, CI: $0.60-0.68]$. The children with $4+$ birth order and birth interval as more than 23 months had a $19 \%$ lower likelihood to be born as LBW [OR:0.8, CI: 0.76-0.86] in comparison to children born as first birth order. Women with higher education status had a $27 \%$ lower likelihood to 
Table 1 Percentage distribution of the study population by background characteristics, India, 2015-16

\begin{tabular}{|c|c|c|}
\hline Background characteristics & Percentage & Sample \\
\hline \multicolumn{3}{|l|}{ Age at index birth (in years) } \\
\hline$\leq 19$ & 14.3 & 18,144 \\
\hline $20-24$ & 44.8 & 57,013 \\
\hline $25-29$ & 28.0 & 35,622 \\
\hline $30-35$ & 10.6 & 13,485 \\
\hline $35+$ & 2.3 & 2876 \\
\hline \multicolumn{3}{|l|}{ Body mass index } \\
\hline Underweight & 24.5 & 29,946 \\
\hline Normal & 57.5 & 75,821 \\
\hline Overweight and Obese & 18.0 & 21,374 \\
\hline \multicolumn{3}{|l|}{ Ante-natal care } \\
\hline No & 5.9 & 8223 \\
\hline Partial & 70.6 & 91,977 \\
\hline Full ${ }^{\mathrm{a}}$ & 23.6 & 26,941 \\
\hline \multicolumn{3}{|l|}{ Birth order and interval } \\
\hline First & 34.9 & 43,295 \\
\hline $2-3 \&<23$ months & 12.8 & 15,263 \\
\hline $2-3 \&>23$ months & 41.0 & 51,640 \\
\hline $4+\&<24$ months & 2.5 & 3643 \\
\hline $4+\&>24$ months & 8.8 & 13,300 \\
\hline \multicolumn{3}{|l|}{ Education } \\
\hline No education & 20.5 & 27,650 \\
\hline Primary & 12.7 & 16,579 \\
\hline Secondary & 52.4 & 66,108 \\
\hline Higher & 14.5 & 16,804 \\
\hline \multicolumn{3}{|l|}{ Caste } \\
\hline Scheduled Caste & 20.5 & 23,074 \\
\hline Scheduled Tribe & 9.6 & 22,755 \\
\hline Other Backward Class & 42.8 & 49,913 \\
\hline Others & 27.1 & 31,399 \\
\hline \multicolumn{3}{|l|}{ Religion } \\
\hline Hindu & 80.3 & 95,539 \\
\hline Muslim & 14.2 & 17,005 \\
\hline Others & 5.4 & 14,597 \\
\hline \multicolumn{3}{|l|}{ Wealth index } \\
\hline Poorest & 17.0 & 23,287 \\
\hline Poorer & 19.8 & 26,643 \\
\hline Middle & 21.1 & 27,214 \\
\hline Richer & 21.9 & 25,895 \\
\hline Richest & 20.2 & 24,102 \\
\hline \multicolumn{3}{|l|}{ Residence } \\
\hline Urban & 34.0 & 36,874 \\
\hline Rural & 66.0 & 90,267 \\
\hline \multicolumn{3}{|l|}{ Sex of the child } \\
\hline Male & 55.5 & 70,380 \\
\hline Female & 44.5 & 56,761 \\
\hline \multicolumn{3}{|l|}{ Region } \\
\hline North & 13.6 & 25,133 \\
\hline Central & 20.1 & 30,284 \\
\hline
\end{tabular}

Table 1 (continued)

\begin{tabular}{|c|c|c|}
\hline Background characteristics & Percentage & Sample \\
\hline East & 23.9 & 25,385 \\
\hline Northeast & 3.8 & 18,059 \\
\hline West & 15.6 & 11,289 \\
\hline South & 22.9 & 16,991 \\
\hline \multicolumn{3}{|l|}{ Source of drinking Water } \\
\hline Not improved & 15.6 & 20,723 \\
\hline Improved ${ }^{b}$ & 84.4 & 106,418 \\
\hline \multicolumn{3}{|l|}{ Type of toilet facility } \\
\hline Not improved & 44.8 & 57,163 \\
\hline Improved ${ }^{c}$ & 55.2 & 69,978 \\
\hline \multicolumn{3}{|l|}{ Type of cooking fuel } \\
\hline Unclean & 56.9 & 78,816 \\
\hline Clean $^{d}$ & 43.1 & 48,325 \\
\hline Total & 100.0 & 127,141 \\
\hline \multicolumn{3}{|c|}{$\begin{array}{l}\text { a Full ANC defined as mother who received four or more antenatal checks, at } \\
\text { least two tetanus toxoid injection, and took iron and folic acid tablets or syrup } \\
\text { for } 100 \text { days or more during their last live birth in the } 5 \text { years preceding the } \\
\text { survey }\end{array}$} \\
\hline \multicolumn{3}{|c|}{$\begin{array}{l}\text { b Include piped water, public taps, standpipes, tube wells, boreholes, protected } \\
\text { dug wells and springs, rainwater, and community reverse osmosis (RO) plants }\end{array}$} \\
\hline \multicolumn{3}{|c|}{$\begin{array}{l}\text { 'Include flush/pour flush toilets to piped sewer systems, septic tanks, and pit } \\
\text { latrines; ventilated improved pit (VIP)/biogas latrines; pit latrines with slabs; and } \\
\text { twin pit/composting toilets }\end{array}$} \\
\hline d Include Electricity, LPG/natural & & \\
\hline
\end{tabular}

have children with LBW than women with no education [OR: 0.73, CI: 0.69-0.79]. Women from the richest wealth quintile had a $21 \%$ lower likelihood to have children with LBW than women from the poorest households [OR: 0.79, CI: 0.73-0.85]. Women from rural areas had lower odds to have LBW than children from urban areas [OR:0.89, CI: 0.86-0.93]. Female newborns had a $23 \%$ higher likelihood to have LBW status than male newborns [OR: 1.23, CI: 1.19 -1.26]. Women who were from the north-eastern region of India had a $49 \%$ lower likelihood to have LBW children than women from the northern region of India [OR:0.51, CI:0.47-0.51]. Similarly, women from households with clean cooking fuel had a 4\% lower likelihood to be LBW than women from households with unclean cook fuel [OR: 0.96, CI: 0.92-0.99].

Figure 1 depicts the concentration curve for children with LBW in India. The curve above the line of equality shows that LBW was concentrated among children from low socio-economic status. The negative value of the concentration index depicts that the outcome variable (LBW here) is concentrated among the poor. The value of $\mathrm{CCI}$ for India was $(-0.05)$.

Figure 2 depicts the concentration curve for children with LBW across six regions of India. The highest CCI was for the north-eastern region $(-0.10)$, followed by the southern region $(-0.09)$ and northern region $(-0.09)$ of 
Table 2 Percentage distribution of low birth weight (LBW: $<2500 \mathrm{~g}$ ) among children by background characteristics, India, 2015-16

\begin{tabular}{|c|c|c|}
\hline Background characteristics & LBW & $P$-value \\
\hline Age at index birth (in Years) & & * \\
\hline$\leq 19$ & 19.9 & \\
\hline $20-24$ & 16.9 & \\
\hline $25-29$ & 16.7 & \\
\hline $30-35$ & 17.1 & \\
\hline $35+$ & 18.5 & \\
\hline Body mass index & & * \\
\hline Underweight & 21.1 & \\
\hline Normal & 16.6 & \\
\hline Overweight and Obese & 14.5 & \\
\hline Ante-natal care & & * \\
\hline No & 22.9 & \\
\hline Partial & 17.8 & \\
\hline Full ${ }^{\mathrm{a}}$ & 14.5 & \\
\hline Birth order and interval & & * \\
\hline First & 18.0 & \\
\hline $2-3 \&<23$ months & 17.7 & \\
\hline $2-3 \&>23$ months & 16.3 & \\
\hline $4+\&<24$ months & 20.3 & \\
\hline $4+\&>24$ months & 17.9 & \\
\hline Education & & * \\
\hline No education & 19.4 & \\
\hline Primary & 19.8 & \\
\hline Secondary & 17.1 & \\
\hline Higher & 13.3 & \\
\hline Caste & & * \\
\hline Scheduled Caste & 18.4 & \\
\hline Scheduled Tribe & 19.3 & \\
\hline Other Backward Class & 17.0 & \\
\hline Others & 16.3 & \\
\hline \multicolumn{3}{|l|}{ Religion } \\
\hline Hindu & 17.6 & \\
\hline Muslim & 16.2 & \\
\hline Others & 15.7 & \\
\hline Wealth index & & * \\
\hline Poorest & 19.6 & \\
\hline Poorer & 18.3 & \\
\hline Middle & 17.6 & \\
\hline Richer & 17.5 & \\
\hline Richest & 14.1 & \\
\hline Residence & & * \\
\hline Urban & 16.5 & \\
\hline Rural & 17.8 & \\
\hline Sex of the child & & * \\
\hline Male & 16.1 & \\
\hline Female & 18.9 & \\
\hline Region & & $*$ \\
\hline North & 19.8 & \\
\hline
\end{tabular}

Table 2 (continued)

\begin{tabular}{|c|c|c|}
\hline Background characteristics & LBW & $P$-value \\
\hline Central & 19.3 & \\
\hline East & 15.7 & \\
\hline Northeast & 13.6 & \\
\hline West & 18.3 & \\
\hline South & 15.9 & \\
\hline \multicolumn{3}{|l|}{ Source of drinking Water } \\
\hline Not improved & 17.8 & \\
\hline Improved ${ }^{b}$ & 17.3 & \\
\hline Type of toilet facility & & * \\
\hline Not improved & 18.8 & \\
\hline Improved ${ }^{c}$ & 16.2 & \\
\hline Type of cooking fuel & & * \\
\hline Unclean & 18.3 & \\
\hline Clean $^{d}$ & 16.1 & \\
\hline Total & 18.2 & \\
\hline
\end{tabular}

LBW Low birth weight

${ }^{*} p<0.05$

${ }^{a}$ Full ANC defined as mother who received four or more antenatal checks, at least two tetanus toxoid injection, and took iron and folic acid tablets or syrup for 100 days or more during their last live birth in the 5 years preceding the survey

${ }^{\mathrm{b}}$ Include piped water, public taps, standpipes, tube wells, boreholes, protected dug wells and springs, rainwater, and community reverse osmosis (RO) plants

'Include flush/pour flush toilets to piped sewer systems, septic tanks, and pit latrines; ventilated improved pit (VIP)/biogas latrines; pit latrines with slabs; and twin pit/composting toilets

${ }^{d}$ Include Electricity, LPG/natural gas, biogas

India while the lowest $\mathrm{CCI}$ was for central $(-0.05)$ and east $(-0.05)$ regions.

Estimates of decomposition analysis for the contribution of various explanatory variables for LBW children in India is presented in Table 4. It was found that the wealth quintile explained $73.6 \%$ of the SES related inequality followed by the region of India $(-44 \%)$ and educational status $(43.4 \%)$ for LBW among children in India. Additionally, BMI of the women (28.4\%), ANC (20.8\%), and residential status $(-15.7 \%)$ explained SES related inequality for LBW among children in India.

\section{Discussion}

In the present paper, we have tried to identify the determinants of a child's LBW by analyzing the fourth round of the National Family Health Survey. We found that LBW of a child was due to the following reasons: (i) Mother's individual characteristics such as her age (below 19 years), low BMI status, with no ANC services and education; (2) Mother's household characteristic such as if she belonged to the poorest wealth quintile, and scheduled caste; (3) If the child was a female and from a higher birth order \& interval. We also found that the LBW of the 
Table 3 Estimates from logistic regression analysis for low birth weight children by their background characteristics, India, 201516

\begin{tabular}{l} 
Background characteristics \\
\hline Age at index birth (in Years) \\
$\leq 19$ \\
$20-24$ \\
$25-29$ \\
$30-35$ \\
$35+$ \\
Body mass index \\
Underweight \\
Normal \\
Overweight and Obese
\end{tabular}

\section{Ante-natal care}

No

Partial

Full ${ }^{\mathrm{a}}$

\section{Birth order and interval}

First

$2-3$ \& $<24$ months

$2-3 \&>23$ months

$4+\&<24$ months

$4+\&>23$ months

\section{Education}

No education

Primary

Secondary

Higher

Caste

Scheduled Caste

Scheduled Tribe

Other Backward Class

Others

Religion

Hindu

Muslim

Others

Wealth index

Poorest

Poorer

Middle

Richer

Richest

\section{Residence}

Urban

Rural

Sex of the child

Male

Female

Region

North

\section{OR $[95 \% \mathrm{Cl}]$}

Ref.

$0.82^{* * *}(0.79-0.86)$

$0.77^{* * *}(0.73-0.81)$

$0.75^{* * *}(0.71-0.80)$

$0.77^{* *}(0.70-0.85)$

$1.27^{* * *}(1.23-1.32)$

Ref.

$0.93^{* * *}(0.89-0.97)$

Ref.

$0.75^{* * *}(0.71-0.8)$

$0.64^{* * *}(0.60-0.68)$

Ref.

$0.89^{* * *}(0.85-0.93)$

$0.84^{* * *}(0.81-0.88)$

0.95(0.87-1.04)

$0.81^{* * *}(0.76-0.86)$

Ref.

1.04(0.99-1.09)

$0.91^{* * *}(0.87-0.95)$

$0.73^{* * *}(0.69-0.79)$

$1.06^{* *}(1.01-1.11)$

$0.93^{* * *}(0.88-0.98)$

0.97(0.93-1.01)

Ref.

Ref.

$0.94 * *(0.90-0.99)$

$0.79^{* * *}(0.74-0.84)$

Ref.

$0.95^{* *}(0.90-0.99)$

$0.91^{* * *}(0.86-0.96)$

$0.91^{* *}(0.85-0.98)$

$0.79^{* * *}(0.73-0.85)$

Ref.

$0.89^{* * *}(0.86-0.93)$

Ref.

$1.23^{* * *}(1.19-1.26)$

Ref.
Table 3 (continued)

\begin{tabular}{ll}
\hline Background characteristics & OR [95\% CI] \\
\hline Central & $0.92^{* * *}(0.88-0.97)$ \\
East & $0.67^{* * *}(0.64-0.71)$ \\
Northeast & $0.51^{* * *}(0.47-0.54)$ \\
West & $0.94^{* *}(0.88-0.99)$ \\
South & $0.84^{* * *}(0.79-0.89)$ \\
Source of drinking Water & \\
Not improved & Ref. \\
Improved & $1.03(0.99-1.07)$ \\
Type of toilet facility & \\
Not improved & Ref. \\
Improved & $1.00(0.96-1.05)$ \\
Type of cooking fuel & \\
Unclean $_{\text {Clean }}{ }^{c}$ & Ref. \\
\hline
\end{tabular}

Ref. Reference category, OR Odds ratio, $\mathrm{Cl}$ Confidence interval

${ }^{* * *} p<0.01 ; * * 0<0.05 ;{ }^{*} p<0.10$

${ }^{a}$ Full ANC defined as women who received four or more antenatal checks, at least two tetanus toxoid injection, and took iron and folic acid tablets or syrup for 100 days or more during their last live birth in the 5 years preceding the survey

${ }^{\mathrm{b}}$ Include piped water, public taps, standpipes, tube wells, boreholes, protected dug wells and springs, rainwater, and community reverse osmosis (RO) plants

' Include flush/pour flush toilets to piped sewer systems, septic tanks, and pit latrines; ventilated improved pit (VIP)/biogas latrines; pit latrines with slabs; and twin pit/composting toilets

${ }^{d}$ Include Electricity, LPG/natural gas, biogas

child was concentrated in the poorest sections of society. Further, the mother's wealth quintile, region and educational status contributed to the maximum while explaining the socio-economic related inequality for LBW among the children in India.

The present study results indicate that women who had low BMI status were more likely to have children with LBW status. This observation is in accordance with a study that shows that girls with low birth weight are likely to give birth to LBW infants [37]. Further, a strong positive relationship is found between the mother's BMI and the child's birth weight [38]. For instance, a secondary analysis of the second round of the National Family Health Survey found that mothers who were underweight were $30 \%$ more likely to have an LBW baby than those women who weighed normal or overweight [25]. The same study also found that mothers' non-use of ANC services increased the risk of LBW of the child. Similar results have been described in other studies $[39,40]$. The study results reveal that the LBW of a child significantly depends if the mother is an adolescent, illiterate and if the child is female; these observations are inconsistent with other studies [25, 39-45]. A cross-sectional study showed that pregnancy during the mother's adolescence 

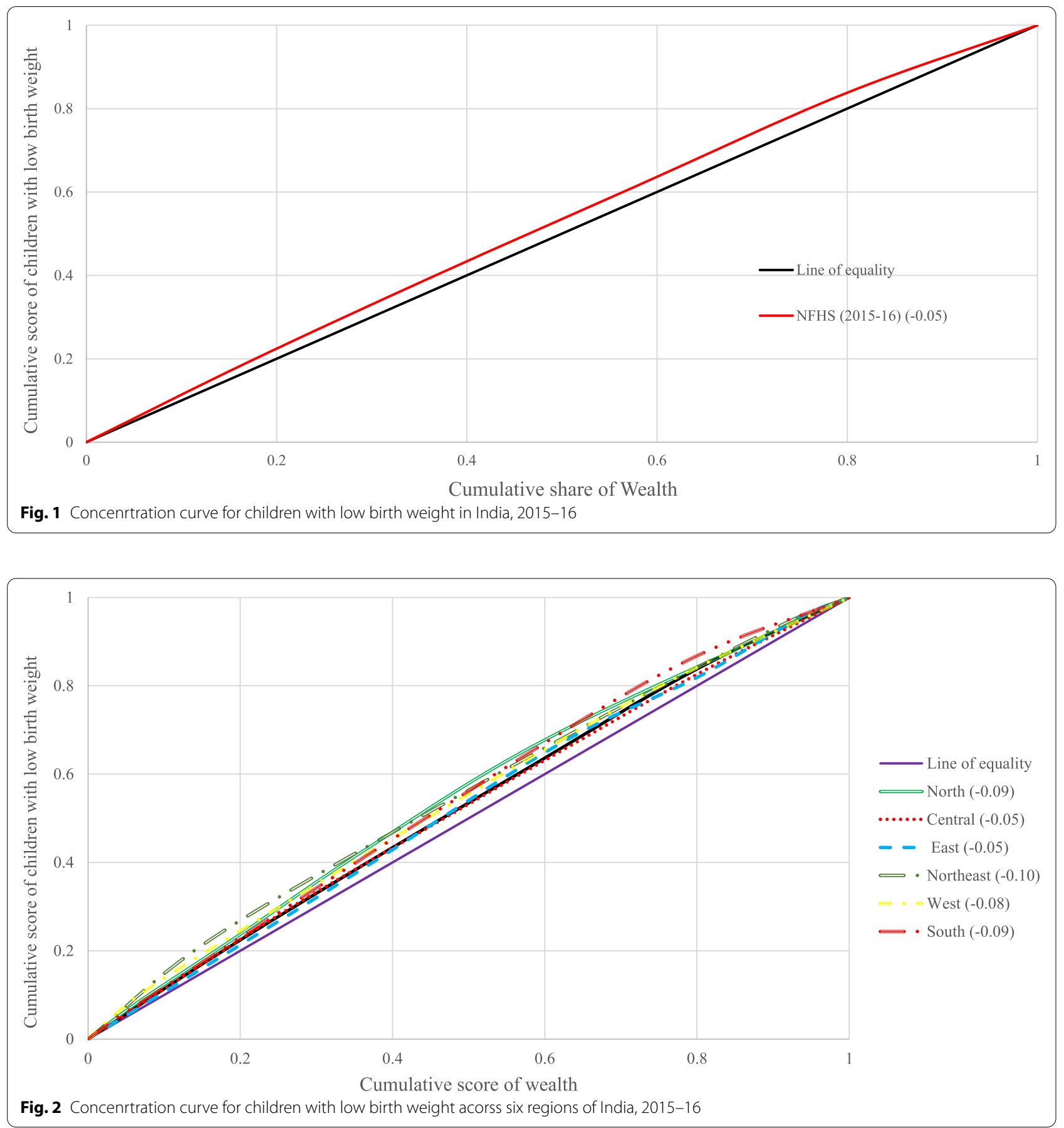

was associated with unfavorable outcomes such as LBW of the infants; however, it was linked to social vulnerability since it was only observed among adolescent mothers without a partner [46]. Often a positive relationship between a mother's education and the child's health is noticed [47]. This may be because educated mothers are aware of newborn care practices, health facilities and ANC services. However, it is argued that illiterate women are less likely to use maternal health care services for delivery assistance [48].

Our study found that female infants had a higher likelihood of being born LBW. Though the study finding is similar to few studies $[45,49]$, it contradicts another finding [50]. Results revealed if a child is of fourth birth order, then the likelihood of LBW declines. We found few studies that suggested LBW was common among first-order 
Table 4 Estimates of decomposition analysis for the contribution of various explanatory variables for low birth weight children in India, 2015-16

\begin{tabular}{|c|c|c|c|c|c|}
\hline Background characteristics & Coefficient & Elasticity & $\mathrm{CCl}$ & $\begin{array}{l}\text { Absolute Contribution } \\
\text { to } \mathrm{CCl}\end{array}$ & $\begin{array}{l}\text { Percentage } \\
\text { contribution }\end{array}$ \\
\hline \multicolumn{6}{|l|}{ Age at index birth } \\
\hline \multicolumn{6}{|l|}{$\leq 19$ (Ref.) } \\
\hline $20-24$ & $-0.196^{* * *}$ & -0.009 & 0.004 & 0.000 & 0.4 \\
\hline $25-29$ & $-0.264^{* * *}$ & -0.003 & 0.073 & 0.000 & 2.6 \\
\hline $30-35$ & $-0.286^{* * *}$ & -0.001 & 0.024 & 0.000 & 0.1 \\
\hline $35+$ & $-0.261^{* *}$ & -0.001 & 0.024 & 0.000 & 0.1 \\
\hline \multicolumn{6}{|l|}{ Body mass index } \\
\hline Underweight & $0.239^{* * *}$ & 0.009 & -0.219 & -0.002 & 21.9 \\
\hline \multicolumn{6}{|l|}{ Normal (Ref.) } \\
\hline Overweight and Obese & $-0.072^{* * *}$ & -0.002 & 0.330 & -0.001 & 6.4 \\
\hline \multicolumn{6}{|l|}{ ANC } \\
\hline \multicolumn{6}{|l|}{ No (Ref.) } \\
\hline Partial & $-0.285^{* * *}$ & -0.031 & -0.056 & 0.002 & -18.6 \\
\hline Full & $-0.446^{* * *}$ & -0.016 & 0.231 & -0.004 & 39.4 \\
\hline \multicolumn{6}{|l|}{ Birth order and interval } \\
\hline \multicolumn{6}{|l|}{ First (Ref.) } \\
\hline $2-3 \&<24$ months & $-0.118^{* * *}$ & -0.002 & -0.046 & 0.000 & -1.1 \\
\hline $2-3 \&>23$ months & $-0.170^{* * *}$ & -0.010 & 0.024 & 0.000 & 2.5 \\
\hline $4+\&<24$ months & -0.050 & 0.000 & -0.397 & 0.000 & -1.3 \\
\hline $4+\&>23$ months & $-0.209^{* * *}$ & -0.003 & -0.374 & 0.001 & -11.6 \\
\hline \multicolumn{6}{|l|}{ Education } \\
\hline \multicolumn{6}{|l|}{ No education (Ref.) } \\
\hline Primary & 0.036 & 0.001 & -0.273 & 0.000 & 3.5 \\
\hline Secondary & $-0.094^{* * *}$ & -0.005 & 0.091 & 0.000 & 5.1 \\
\hline Higher & $-0.308^{* * *}$ & -0.006 & 0.579 & -0.003 & 34.8 \\
\hline \multicolumn{6}{|l|}{ Caste } \\
\hline Scheduled Caste & $0.054^{* *}$ & 0.000 & -0.158 & 0.000 & 0.5 \\
\hline Scheduled Tribe & $-0.077^{* * *}$ & 0.001 & -0.396 & 0.000 & 2.1 \\
\hline Other Backward Class & -0.030 & -0.002 & 0.036 & 0.000 & 0.6 \\
\hline \multicolumn{6}{|l|}{ Others (Ref.) } \\
\hline \multicolumn{6}{|l|}{ Religion } \\
\hline \multicolumn{6}{|l|}{ Hindu (Ref.) } \\
\hline Muslim & $-0.058^{* *}$ & -0.002 & 0.036 & 0.000 & 0.6 \\
\hline Others & $-0.233^{* * *}$ & -0.001 & 0.221 & 0.000 & 1.4 \\
\hline \multicolumn{6}{|l|}{ Wealth index } \\
\hline \multicolumn{6}{|l|}{ Poorest (Ref.) } \\
\hline Poorer & $-0.056^{* *}$ & -0.002 & -0.463 & 0.001 & -8.5 \\
\hline Middle & $-0.093^{* * *}$ & -0.003 & -0.055 & 0.000 & -1.7 \\
\hline Richer & $-0.089^{* *}$ & -0.003 & 0.376 & -0.001 & 10.1 \\
\hline Richest & $-0.240^{* * *}$ & -0.009 & 0.798 & -0.007 & 73.7 \\
\hline \multicolumn{6}{|l|}{ Residence } \\
\hline \multicolumn{6}{|l|}{ Urban (Ref.) } \\
\hline Rural & $-0.114^{* * *}$ & -0.007 & -0.212 & 0.001 & -15.7 \\
\hline \multicolumn{6}{|l|}{ Sex of the child } \\
\hline \multicolumn{6}{|l|}{ Male (Ref.) } \\
\hline Female & $0.204^{* * *}$ & 0.013 & -0.002 & 0.000 & 0.3 \\
\hline \multicolumn{6}{|l|}{ Region } \\
\hline North (Ref.) & & & & & \\
\hline
\end{tabular}


Table 4 (continued)

\begin{tabular}{|c|c|c|c|c|c|}
\hline Background characteristics & Coefficient & Elasticity & $\mathrm{CCl}$ & $\begin{array}{l}\text { Absolute Contribution } \\
\text { to } \mathrm{CCl}\end{array}$ & $\begin{array}{l}\text { Percentage } \\
\text { contribution }\end{array}$ \\
\hline Central & $-0.080^{* * *}$ & -0.004 & -0.107 & 0.000 & -4.5 \\
\hline East & $-0.394^{* * *}$ & -0.015 & -0.340 & 0.005 & -56.2 \\
\hline Northeast & $-0.682^{* * *}$ & -0.003 & -0.220 & 0.001 & -7.1 \\
\hline West & $-0.066^{* *}$ & -0.003 & 0.158 & -0.001 & 5.8 \\
\hline South & $-0.175^{* * *}$ & -0.008 & 0.202 & -0.002 & 18.0 \\
\hline \multicolumn{6}{|l|}{ Source of drinking Water } \\
\hline \multicolumn{6}{|l|}{ Not improved (Ref.) } \\
\hline Improved $^{b}$ & 0.030 & -0.002 & 0.005 & 0.000 & 0.1 \\
\hline \multicolumn{6}{|l|}{ Type of toilet facility } \\
\hline \multicolumn{6}{|l|}{ Not improved (Ref.) } \\
\hline Improved $^{c}$ & 0.003 & -0.001 & 0.321 & 0.000 & 4.8 \\
\hline \multicolumn{6}{|l|}{ Type of cooking fuel } \\
\hline \multicolumn{6}{|l|}{ Unclean (Ref.) } \\
\hline Clean $^{d}$ & $-0.039^{*}$ & 0.002 & 0.472 & 0.001 & -8.1 \\
\hline Calculated CCI & & & & -0.009 & \\
\hline Actual CCI & & & & -0.056 & \\
\hline Residual & & & & -0.047 & \\
\hline
\end{tabular}

Ref. Reference category, $\mathrm{CCl}$ Concentration index

*** $p<0.01$; ${ }^{* *} p<0.05 ;{ }^{*} p<0.10$

${ }^{a}$ Full ANC defined as women who received four or more antenatal checks, at least two tetanus toxoid injection, and took iron and folic acid tablets or syrup for 100 days or more during their last live birth in the 5 years preceding the survey

${ }^{\mathrm{b}}$ Include piped water, public taps, standpipes, tube wells, boreholes, protected dug wells and springs, rainwater, and community reverse osmosis (RO) plants

' Include flush/pour flush toilets to piped sewer systems, septic tanks, and pit latrines; ventilated improved pit (VIP)/biogas latrines; pit latrines with slabs; and twin pit/ composting toilets

d Include Electricity, LPG/natural gas, biogas

babies [51, 52] and if the child is of second and higher birth order, then the odds of LBW are low [45]. Results of bivariate and multivariate techniques used in the study indicate that belonging to the poorest wealth quintile is a critical determinant of a child's LBW. For instance, women belonging to low socio-economic status are at a greater risk of being underweight [53], which eventually leads to giving birth to an LBW child. Few other studies showed that the LBW of a child is determined by the mother's economic class $[40,44,45]$. Again, the LBW of a child decreased if the household used clean cooking fuel and improved toilet facilities. It is in line with previous studies $[25,43,54]$. Poor sanitation practices increase the odds of LBW newborns [51]. This shows how a woman's nutrition, use of ANC services, environmental factors and infections are influenced by various socio-economic factors like food security, poverty, and women's status [25]. Perhaps, the above findings highlight the importance of the woman's individual or household's financial status that influences access to improved toilet facilities, clean cooking fuel and better nutritional status, which are all necessary determinants to avoid giving birth to an LBW newborn.
The socio-economic inequality in LBW newborns in India was measured by Concentration Index and Concentration curve. The analysis showed that LBW is mostly concentrated in the North-eastern regions of the country, followed by the South and Northern parts of the country. However, a study shows that the Northern states of India had the highest concentration of LBW children [5]. Literary evidence reveals that pregnant women suffering from anaemia are most likely to give birth to LBW babies $[55,56]$. Since the prevalence of anaemia in the north-eastern states is quite high $[57,58]$, it could be a possible explanation for such a result. Further, poor public health system [59] and low coverage of reproductive, maternal, neonatal and child health interventions in the north-eastern states $[47,60]$ are few other justifications for the high concentration of LBW in those regions of the country.

\section{Limitation}

The present study uses a nationally representative recently published sample of a well-known large-scale survey in India. Therefore, the study results can be generalised well. However, we acknowledge some limitations 
too. First, because of the cross-sectional nature of the data, we could not draw any causal relationship between the variables. Second, another limitation of the cross-sectional household survey is that birth weight is estimated from the records of the newborn in health facilities. However, the birth weight of those born at home are not available.

\section{Conclusion}

Since India contributes to the highest infant LBW in the southern region, identifying the risk factors of LBW has significant policy implications. Adequate attention should be given to the mother's nutritional status; timely intake of iron and folic acid tablets during pregnancy can be a way of achieving it. Awareness of health education and usage of health services during pregnancy are few other important things that can be taken up at the household and community level. Further, there is a need to improve the coverage and awareness of the ANC program. Hence, the role of the health workers is of utmost importance. Programs on maternal health services can be merged with maternal nutrition to bring about an overall decline in the LBW of children in India.

\section{Abbreviations}

CC: Concentration curve; Cl: Confidence interval; CCl: Concentration index; NFHS: National Family Health Survey; LBW: Low birth weight; ANC: Ante-natal care; OR: Odds Ratio; BMI: Body mass index; UNICEF: United Nations International Children's Emergency Fund; WHO: World Health Organization.

\section{Supplementary Information}

The online version contains supplementary material available at https://doi. org/10.1186/s12887-021-02988-3.

Additional file 1: Table S1. STROBE Flow Diagram.

\section{Acknowledgements}

Not applicable.

\section{Authors' contributions}

The concept was drafted by SS, PSM, PK and RB; SS and PK contributed to the analysis design, PSM and DS advised on the paper and assisted in paper conceptualisation. SS contributed in the comprehensive writing of the article. All authors read and approved the final manuscript.

\section{Authors' information}

Prem Shankar Mishra is a PhD Research Scholar at Population Research Centre at Institute for Social and Economic Change (ISEC), Bangalore.

Debashree Sinha is a PhD scholar at the International Institute for Population Sciences Mumbai, India. She has a master's degree in Economics and Population Sciences. Her research interests include economic development, gender and development and ageing.

Pradeep Kumar completed his M.Phil in Population studies and currently pursuing his PhD in Population studies from International Institute for Population. His area of interest is Ageing and reproductive health among married women in India.

Shobhit Srivastava completed his M.Phil in Population studies and currently pursuing his PhD in Population studies from International Institute for Population. His area of interest is Public health issues among adults in India.
Rahul Bawankule is currently pursuing his PhD in Population studies from International Institute for Population. His area of interest is Public health issues among children in India.

Funding

Authors did not receive any funding to carry out this research.

\section{Availability of data and materials}

The study utilizes secondary source of data which is freely available in public domain through https://dhsprogram.com/methodology/survey-search.cfm? pgtype $=$ main $\&$ SrvyTp $=$ country $\&$ ctry_id $=57$.

\section{Declarations}

\section{Ethics approval and consent to participate}

The data is freely available in public domain and survey agencies that conducted the field survey for the data collection have collected a prior consent from the respondent. Local ethics committee of International Institute for Population Sciences (IIPS), Mumbai, ruled that no formal ethics approval was required to carry out research from this data source.

\section{Consent for publication}

Not applicable.

\section{Competing interests}

The authors declare that they have no competing interests.

\section{Author details}

${ }^{1}$ Population Research Centre, Institute for Social and Economic Change, Bengaluru, Karnataka 560072, India. ${ }^{2}$ Department of Development Studies, International Institute for Population Sciences, Mumbai, Maharashtra 400088, India. ${ }^{3}$ Department of Mathematical Demography \& Statistics, International Institute for Population Sciences, Mumbai, Maharashtra 400088, India. ${ }^{4}$ Department of Public Health \& Mortality Studies, International Institute for Population Sciences, Mumbai, Maharashtra 400088, India.

Received: 15 October 2020 Accepted: 3 November 2021

Published online: 19 November 2021

\section{References}

1. Chawanpaiboon S, Vogel JP, Moller AB, et al. Global, regional, and national estimates of levels of preterm birth in 2014: a systematic review and modelling analysis. Lancet Glob Health. 2019;7:e37-46.

2. UNICEF \&WHO. Low birthweight estimates: levels and trends 200-2015. Geneva: World Health Organization; 2019. p. 1-36.

3. Hack M, Flannery DJ, Schluchter M, et al. Outcomes in young adulthood for very-low-birth-weight infants. N Engl J Med. 2002;346:149-57.

4. UNICEF and WHO. Low birthweight: country, regional and global estimates; 2004. https://doi.org/10.1787/9789264183902-17-en. Epub ahead of print 2004

5. Chellan R, Lopamudra P, Kulkarni PM. Incidence of low-birth-weight in India: regional variations and socio-economic disparities. J Health Dev. 2007:3:147-62.

6. Narayanan I. Care of the low birthweight infant in developing countries. Ann Trop Paediatr. 1986:6:11-5.

7. Bhue PK, Biswal P. Association between maternal risk factors and low birth weight: a hospital based cross-sectional study in Western Odisha, India. Int J Med Res Prof. 2020;6:1-8.

8. Park H-J, Son M. Socioeconomic disparities in pregnancy outcome and infant mortality: extremely low birth weight and very low birth weight infants in Korea, 1995-2010. Health Policy Manag. 2015;25:277-84.

9. Mavalankar DV, Gray RH, Trived CR. Risk factors for preterm and term low birthweight in Ahmedabad, India. Int J Epidemiol. 1992;21:263-72.

10. Rauhut D. A Rawls-Sen approach to spatial injustice. Soc Sci Spectr. 2018;4:109-22.

11. Kader M, Perera NKP. Socio-economic and nutritional determinants of low birth weight in India. N Am J Med Sci. 2014;6:302-8. 
12. Chakraborty P, Anderson AK. Maternal autonomy and low birth weight in India. J Women's Health. 2011;20:1373-82.

13. Abeywickrama G, Padmadas SS, Hinde A. Social inequalities in low birthweight outcomes in Sri Lanka: evidence from the demographic and health survey 2016. BMJ Open. 10:e037223. https://doi.org/10.1136/bmjopen2020-037223 Epub ahead of print 2020.

14. Martinson ML, Reichman NE. Socioeconomic inequalities in low birth weight in the United States, the United Kingdom, Canada, and Australia. Am J Public Health. 2016;106:748-54.

15. Khan N, Mozumdar A, Kaur S. Determinants of low birth weight in India: an investigation from the National Family Health Survey. Am J Hum Biol. 2020:32:1-17.

16. Shirisha P. Socioeconomic determinants of nutritional status among 'Baiga' tribal children in Balaghat district of Madhya Pradesh: a qualitative study. PLoS One. 2019;14:1-21.

17. Conde-Agudelo A, Rosas-Bermúdez A, Kafury-Goeta AC. Birth spacing and risk of adverse perinatal outcomes: a meta-analysis. J Am Med Assoc. 2006:295:1809-23.

18. Moreira AIM, Sousa PRMD, Sarno F. Low birth weight and its associated factors. Einstein. 2018:16:1-6.

19. Khattar D, Awasthi S, Das V. Residential environmental tobacco smoke exposure during pregnancy and low birth weight of neonates: case control study in a public hospital in Lucknow, India. Indian Pediatr. 2013;50:134-8.

20. Amano S, Shrestha BP, Chaube SS, et al. Effectiveness of female community health volunteers in the detection and management of low-birth-weight in Nepal. Rural Remote Health. 2014;14:1-11.

21. Snyder R, Lyon N, Hertel E, et al. Pregnancy and infant health indicators among Asian and Pacific Islanders within the State of Michigan: 2016 report. 2016.

22. Darmstadt GL, KumarV, Shearer JC, et al. Validation of accuracy and community acceptance of the BIRTHweigh III scale for categorizing newborn weight in rural India. J Perinatol. 2007;27:602-8.

23. IIPS \& ICF. India National Family Health Survey NFHS-4 2015-16. Mumbai: IIPS and ICF; 2017.

24. Patel V, Prince M. Maternal psychological morbidity and low birth weight in India. Br J Psychiatry. https://doi.org/10.1192/bjp.bp.105.012096. Epub ahead of print 2006

25. Dharmalingam A, Navaneetham K, Krishnakumar CS. Nutritional status of mothers and low birth weight in India. Matern Child Health J. 2010:14:290-8.

26. Kramer MS. Determinants of low birth weight: methodological assessment and meta-analysis. Bulletin of the world health organization. 1987:65(5):663.

27. Nishida C, Barba C, Cavalli-Sforza T, et al. Appropriate body-mass index for Asian populations and its implications for policy and intervention strategies. Lancet. https://doi.org/10.1016/S0140-6736(03)15268-3 Epub ahead of print 2004.

28. Srivastava S, Kumar S. Does socio-economic inequality exist in micronutrients supplementation among children aged 6 - 59 months in India? Evidence from National Family Health; 2021. p. 1-12.

29. Kumar P, Dhillon P. Household-and community-level determinants of low-risk Caesarean deliveries among women in India. Journal of biosocial science. 2021;53(1):55-70.

30. Kumar P, Patel R, Chauhan $S$, et al. Does socio-economic inequality in infant mortality still exists in India? An analysis based on National Family Health Survey 2005-06 and 2015-16. Clin Epidemiol Glob Health. 2020;9:116-22.

31. Kumar P, Sharma H, Sinha D. Socio-economic inequality in anaemia among men in India: a study based on cross-sectional data. BMC Public Health. 2021:21:1-12

32. Srivastava S, Patel R, Chauhan S, Kumar P, Gupte SS, Bansod DW. Decomposing socio-economic inequality for routine medical check-ups among older adults in India. 2020.

33. Singh SK, Srivastava S, Chauhan S. Inequality in child undernutrition among urban population in India: a decomposition analysis. BMC Public Health. 2020;20:1852.

34. Srivastava S, Purkayastha $\mathrm{N}$, Chaurasia $\mathrm{H}$, et al. Socioeconomic inequality in psychological distress among older adults in India: a decomposition analysis. BMC Psychiatry. 2021;21:179.

35. Wagstaff A, O'Donnell O, Van Doorslaer E, Lindelow M. Analyzing health equity using household survey data: a guide to techniques and their implementation. World Bank Publications; 2007.

36. Wagstaff $A$, Paci $P$, van Doorslaer E. On the measurement of inequalities in health. Soc Sci Med. 1991;33:545-57.
37. Ramakrishnan U, Martorell R, Schroeder DG, Flores R. Role of intergenerational effects on linear growth. J Nutr. 1999;129(2):544S-9S.

38. Kulkarni B, Shatrugna V, Balakrishna N. Maternal lean body mass may be the major determinant of birth weight: a study from India. Eur J Clin Nutr. 2006;60:1341-4.

39. Kader M, Perera NKP. Socio-economic and nutritional determinants of low birth weight in India. N Am J Med Sci. 2014:6:1-7.

40. Acharya D, Singh JK, Kadel R, et al. Maternal factors and utilization of the antenatal care services during pregnancy associated with low birth weight in rural Nepal: analyses of the antenatal care and birth weight records of the MATRI-SUMAN trial. Int J Environ Res Public Health. 2018:15:1-14.

41. Hirve SS, Ganatra BR. Determinants of low birth weight: a community based prospective cohort study. Indian Pediatr. 1994;31:1221.

42. Guimarães AM, Bettiol H, Souza LD, et al. Is adolescent pregnancy a risk factor for low birth weight? Gravidez na adolescência é fator de risco para o baixo peso ao nascer? Abstract. Rev Saúde Pública. 2013:47:11-9.

43. Dičkutè J, Padaiga Z, Nadisauskiene RJ, et al. Maternal socio-economic factors and the risk of low birth weight in Lithuania. Medicina. 2004;40:475-81.

44. Deshpande Jayant D, Phalke DB, Bangal VB, et al. Maternal risk factors for low birth weight neonates: a hospital based case- control study in rural area of Western Maharashtra, India. Natl J Community Med. 2011;2:394-8.

45. Khan N, Mozumdar A, Kaur S. Determinants of low birth weight in India: An investigation from the National Family Health Survey. Am J Human Biol. 2020;32(3):e23355.

46. Guimarães AM, Bettiol H, Souza LD, et al. Is adolescent pregnancy a risk factor for low birth weight? Rev Saude Publica. 2013;47:11-9.

47. Panda BK, Kumar G, Awasthi A. District level inequality in reproductive, maternal, neonatal and child health coverage in India. BMC Public Health. 2020;20:1-10.

48. Navaneetham K, Dharmalingam A. Utilization of maternal health care services in Southern India. Soc Sci Med. 2002;9536:1-41.

49. Kaushal S, Misra S, Gupta S, et al. A study of maternal factors and birth weight in a border district pf Uttar Pradesh: a hospital based study. Indian J Community Health. 2012;24:86-90.

50. Rahman K, Bhuyan AR, Ullah A. Incidence and clinical profile of low birth weight (LBW) babies: a rural tertiary care hospital based study. New Indian J OBGYN. 2015;2:43-5.

51. Boratne D, Gupta S, Datta SS, et al. Determinants of low birth weight in rural Wardha, Central India. Indian J Matern Child Health. 2011;14:1-10.

52. Nair NS, Rao RP, Chandrashekar S, et al. Socio-demographic and maternal determinants of low birth weight: a multivariate approach. Indian J Pediatr. 2000;67:9-14.

53. Subramanian SV, Smith GD. Patterns, distribution, and determinants of under- and overnutrition: a population-based study of women in India. Am J Clin Nutr. 2006;84:633-40.

54. Racape J, Schoenborn C, Sow M, Alexander S, De Spiegelaere M. Are all immigrant mothers really at risk of low birth weight and perinatal mortality? The crucial role of socio-economic status. BMC pregnancy and childbirth. 2016:16(1):1-0.

55. Basanti N, Devi NR, Devi NJ, et al. Prevalence and determinants of severe anaemia among antenatal women attending a tertiary care hospital in Manipur. Paripex Indian J Res. 2020;9(1):111-4.

56. Kalaivani K. Prevalence \& consequences of anaemia in pregnancy. Indian J Med Res. 2009;130:627-33.

57. Dey S, Goswami S, Goswami M. Prevalence of anaemia in women of reproductive age in Meghalaya: a logistic regression analysis. Turk J Med Sci. 2010:40:783-9.

58. Dubey DK, Nath DC. Regional models assessing region-specific determinants of low birth weight in India. Curr Sci. 2019;116:1674-82.

59. Hota PK. National rural health mission. Indian J Public Health. 2005;XXXXIX:107-10.

60. Rai RK. Tracking women and children in a Continuum of Reproductive, Maternal, Newborn, and Child Healthcare (RMNCH) in India. Journal of epidemiology and global health. 2014;4(3):239-43.

\section{Publisher's Note}

Springer Nature remains neutral with regard to jurisdictional claims in published maps and institutional affiliations. 